\title{
The RF Energy Harvesting Antennas Operating in Commercially Deployed Frequency Bands: A Comparative Study
}

\author{
M. Mrnka, P. Vasina, M. Kufa, V. Hebelka, and Z. Raida \\ Department of Radio Electronics, Brno University of Technology, 61600 Brno, Czech Republic \\ Correspondence should be addressed to M. Mrnka; xmrnka01@stud.feec.vutbr.cz
}

Received 7 December 2015; Revised 3 March 2016; Accepted 10 March 2016

Academic Editor: Yvan Duroc

Copyright (C) 2016 M. Mrnka et al. This is an open access article distributed under the Creative Commons Attribution License, which permits unrestricted use, distribution, and reproduction in any medium, provided the original work is properly cited.

\begin{abstract}
This paper deals with suitable antennas for energy harvesting, which is a growing research field due to the utilization of nowadays ubiquitous and abundant RF energy. Four types of basic antenna structures suitable for harvesting applications, namely, the patch antenna, slot antenna, modified inverted $\mathrm{F}$ antenna, and dielectric resonator antenna, are compared from the viewpoint of reflection coefficient, efficiency, radiation patterns, and dimensions. The frequencies of interest were chosen so that they cover several main wireless systems operating between $0.8 \mathrm{GHz}$ and $2.6 \mathrm{GHz}$, that is, GSM, UMTS, and WiFi.
\end{abstract}

\section{Introduction}

The RF energy harvesting refers to the utilization of ubiquitous RF energy transmitted by different wireless systems to remotely feed electronic devices with low-power consumption [1]. Other forms of energy could be harvested instead of RF radiation [2] (i.e., heat, light, and vibrations); however, only RF harvesting is discussed in this paper.

The basic RF harvester architecture includes an antenna followed by a matching circuitry and a rectifier; rectified DC voltage can then be increased using step-up converters or voltage multipliers and accumulated in a battery or a capacitor. Besides low RF power levels, the efficiency of the harvester's electronic circuitry poses major limitation, since it is nonlinear and strongly depends on input power levels $[1,3]$. Possible RF energy resources suitable for harvesting comprise mostly the signals of the communication systems like GSM, UMTS, LTE, and WiFi (IEEE 802.11).

The simplest harvesting devices operate over only one frequency band [4]; narrowband antennas are thus sufficient for harvesting with such circuits. However, in order to accumulate as much energy as possible it is desirable to utilize the ambient RF power of multiple wireless systems. In these scenarios, multiband and wideband antennas become necessary. The RF energy harvesting antenna must satisfy other specific requirements related to its application area.
Due to considerably low-power densities, highly efficient radiators operating at desired frequencies and polarization states with omnidirectional/hemispherical radiation patterns are preferred.

Energy harvesting process (the conversion from RF to DC) itself is not considered in the paper. All antennas are matched to $50-\mathrm{ohm}$ transmission line and not to specific input impedance of harvesting circuits; however, some commercially available RF harvesting circuits [4] have input impedance of $50 \mathrm{ohms}$. The properties of antennas are evaluated at their input ports; any mismatch between the antenna's input impedance and the harvesting circuitry is not taken into account, as the paper focuses only on the antenna part of the harvesting chain.

The performance of four different antenna concepts suitable for RF energy harvesting is compared in this paper. Three of the antennas represent multiband structures and one wideband structure. Every antenna is described in a separate section of the paper and their performance in terms of input matching and radiation efficiency is compared in common plots.

Section 2 gives a very brief overview of the antenna structures under investigation. Sections 3 to 6 deal with the design and discuss achieved performance of the different antenna types and, finally, the paper is concluded by short summarization in Section 7. 


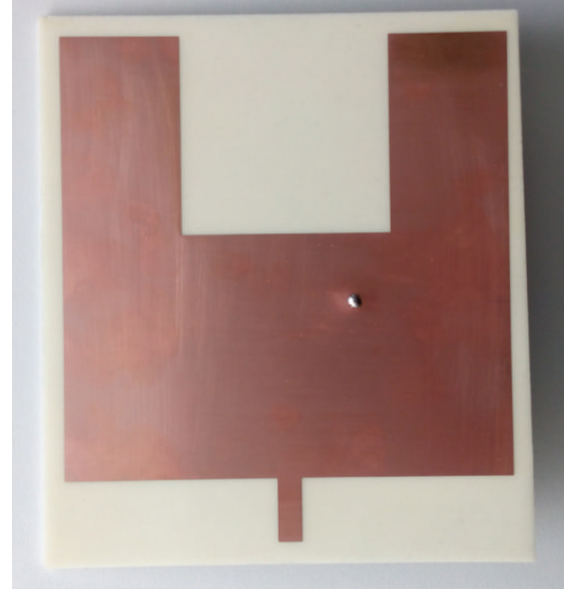

(a)

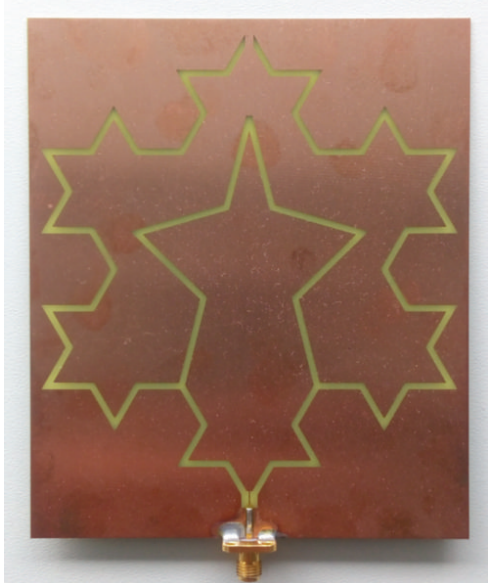

(b)

FIGURE 1: Manufactured multiband patch antenna (a) and dual-band Koch fractal antenna (b).

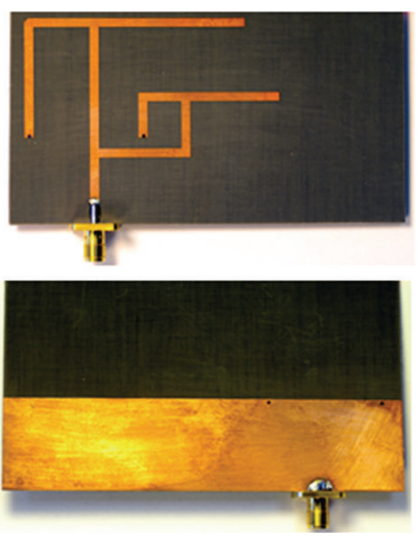

(a)

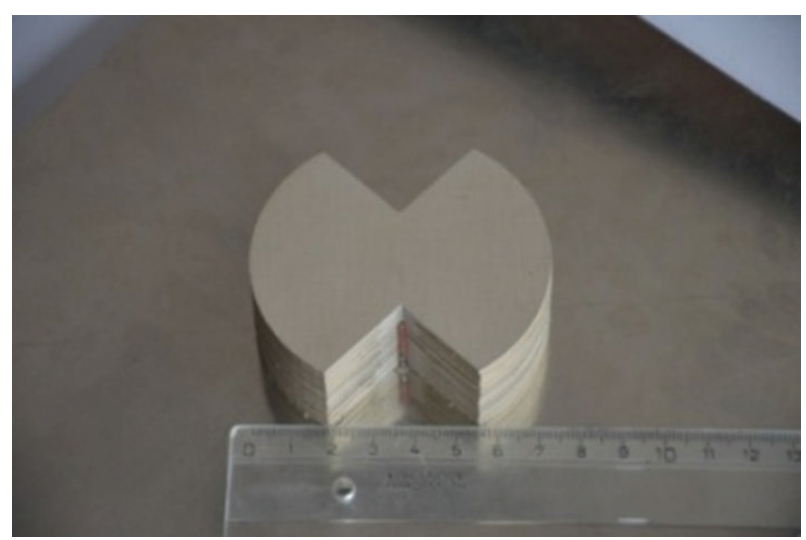

(b)

Figure 2: Dual-band IFA (a) and wideband bow-tie DRA (b).

\section{Antennas for RF Energy Harvesting}

As discussed in Introduction, three multiband and one wideband structures are selected and designed and their performance was compared for the purpose of this paper. The multiband structures are patch antenna, fractal slot antenna, and modified inverted F antenna (IFA). On the other hand, bow-tie shaped dielectric resonator antenna (DRA) represents the wideband approach. The photographs of all the manufactured antennas are shown in Figures 1 and 2.

Even though the design process and achieved performance of the antennas are discussed in separate chapters, the direct comparison of the measured frequency responses of the reflection coefficient on the antenna inputs is given in Figure 3.

Very important parameter of the antennas used in energy harvesting is their radiation efficiency which is related to the losses (dielectric, conducting) and total efficiency, which in addition takes into account the mismatch loss between the antenna and its feed. Simulation results of the total efficiency of the antennas are therefore compared in Figure 4. The efficiency is a critical parameter in energy harvesting due to very low-power densities of available RF resources.

\section{Multiband Patch Antenna}

Nowadays, several papers focus on a planar patch antenna design, which plays a main role in the area of energy harvesting. However, many patch antennas were designed to cover a single frequency band. Specifically, a $377 \Omega$ patch antenna for energy harvesting, which works at downlink range of GSM 900, was described in [5]. A circularly polarized patch antenna was proposed for the same frequency. The antenna uses a partially ground plane for dimension reduction and a defected ground plane with circular slot for suppression of unwanted radiation at harmonic frequencies [6]. On the other hand, several papers are focused on the design of double-band planar patch antennas for energy harvesting. Typically, a patch antenna with additional two slots over this patch was presented in [7]. The antenna works at frequencies 


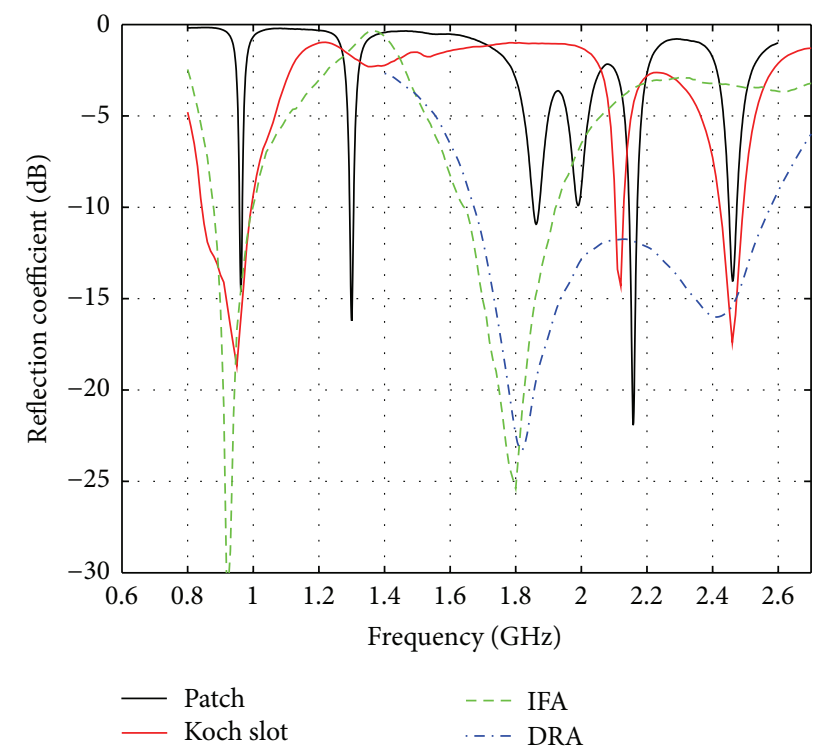

FIgURE 3: Comparison of measured reflection coefficient of designed antennas.

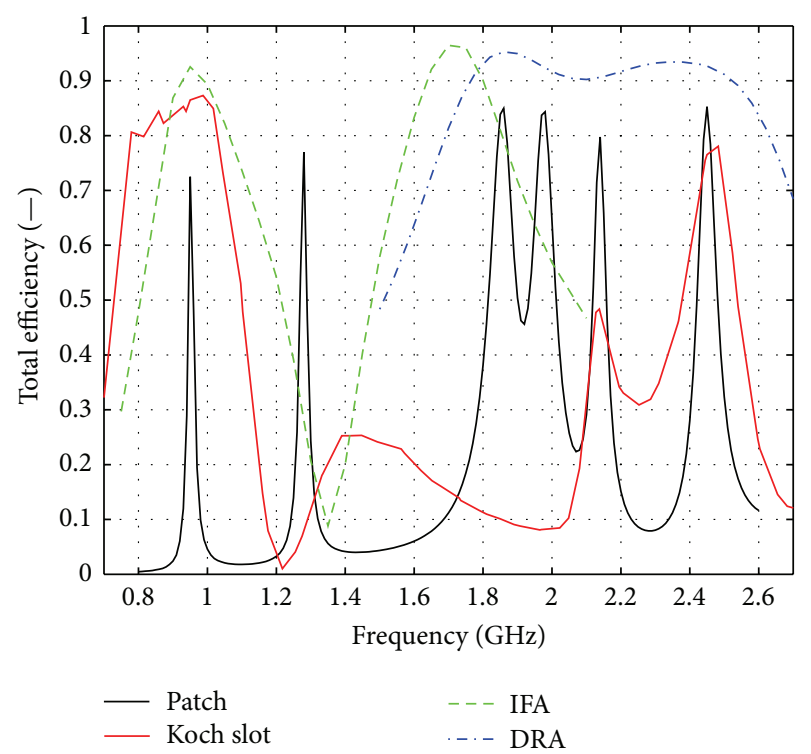

FIGURE 4: Total efficiencies of the antennas (simulation results).

$2.1 \mathrm{GHz}(3 \mathrm{G})$ and $2.4 \mathrm{GHz}(\mathrm{WiFi})$. Some papers describe antenna arrays for energy harvesting such as $2 \times 1$ edge-fed quarter wave circularly polarized antenna array presented in [8] as well as a $4 \times 4$ patch array proposed in [9]. Nevertheless, a four-band planar patch antenna for energy harvesting, which covers the most important frequency bands such as GSM 900, GSM 1800, 3G, and $2.4 \mathrm{GHz} \mathrm{WiFi}$, has not been published yet.

In this section, a four-band planar patch antenna for energy harvesting is discussed. The patch antenna is a good candidate for energy harvesting due to its low weight, ease to manufacture, low profile, and high radiation efficiency. This antenna was designed and simulated in CST Microwave

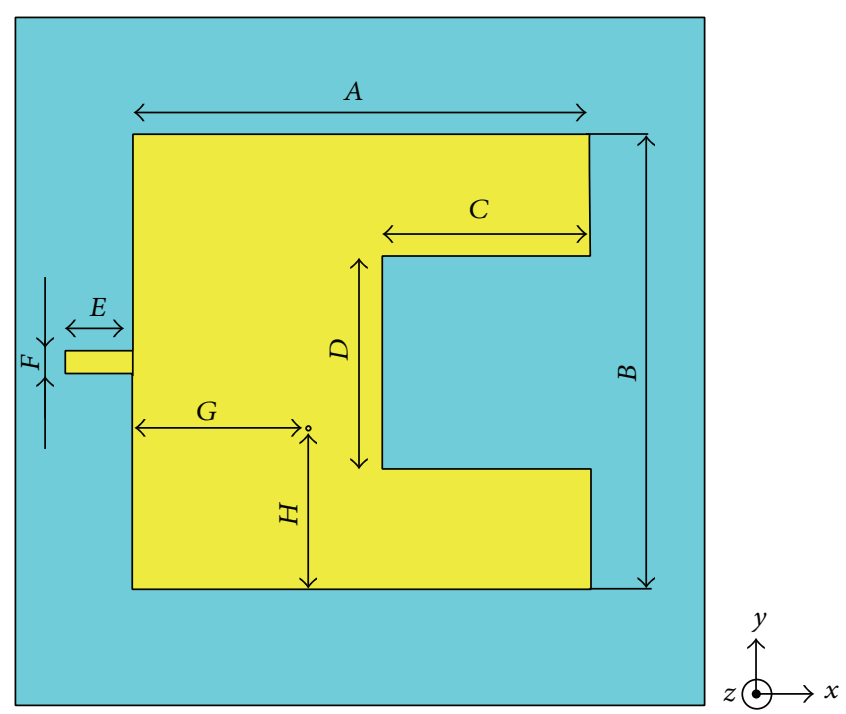

FIgURE 5: Geometry of the four-band patch antenna for energy harvesting.

Studio and optimized at four frequency bands. Specifically, the first two ranges are focused on GSM 900 and on GSM 1800. The third band works at frequency of $2.1 \mathrm{GHz}$, that is, $3 \mathrm{G}$ band, and finally the fourth range covers the $2.4 \mathrm{GHz}$ WiFi band. Naturally, the antenna works with the same polarization at all downlink frequency ranges.

As mentioned, the patch antenna works at the four most important frequencies for energy harvesting. The first band, GSM 900, was chosen, where the antenna uses the fundamental mode $\mathrm{TM}_{10}$ in the area $A \times B$ (Figure 5) and in this band, we can obtain a realized gain of $7.47 \mathrm{dBi}$ and fractional bandwidth $0.75 \%$. The second band is GSM 1800 , where the antenna works with the mode $\mathrm{TM}_{20}$ in the area $A \times B$. In this case, the realized gain of the antenna is $8.42 \mathrm{dBi}$ and the fractional bandwidth $1.50 \%$. The third band is focused on $3 \mathrm{G}$ networks at frequency $2.1 \mathrm{GHz}$. At this frequency, the antenna works with the higher mode in the area $A \times B$ (mode $\mathrm{TM}_{21}$ ), where the edged area $C \times D$ plays a dominant role. The realized gain is about $7.72 \mathrm{dBi}$ and the fractional bandwidth is $0.61 \%$. The last important frequency band which was chosen is the WiFi $2.4 \mathrm{GHz}$. Due to the areas $E \times F$ and the edged area $C \times D$, the antenna works in this band very well with the realized gain $8.3 \mathrm{dBi} ; 0.92 \%$ fractional bandwidth was achieved. In this case, the main area of the patch, that is, $A \times B$, resonates with $\mathrm{TM}_{22}$ mode. The total efficiency is higher than $70 \%$ for all the investigated frequency ranges, specifically, $74 \%$ in the band GSM $900,86 \%$ in the band GSM $1800,80 \%$ in the $3 \mathrm{G}$ band, and $85 \%$ in the WiFi band.

The patch antenna was designed on the substrate FloamClad with dielectric constant 1.2 and thickness of the substrate $2.54 \mathrm{~mm}$. The structure of this antenna is shown in Figure 5 and dimensions of the structure are as follows: $A=133 \mathrm{~mm}$, $B=132 \mathrm{~mm}, C=60 \mathrm{~mm}, D=62 \mathrm{~mm}, E=19 \mathrm{~mm}$, $F=7 \mathrm{~mm}, G=52.5 \mathrm{~mm}$, and $H=46 \mathrm{~mm}$.

The simulated and measured copolarization in the $E$ plane and the $H$-plane for the bands GSM 900, GSM 1800, 


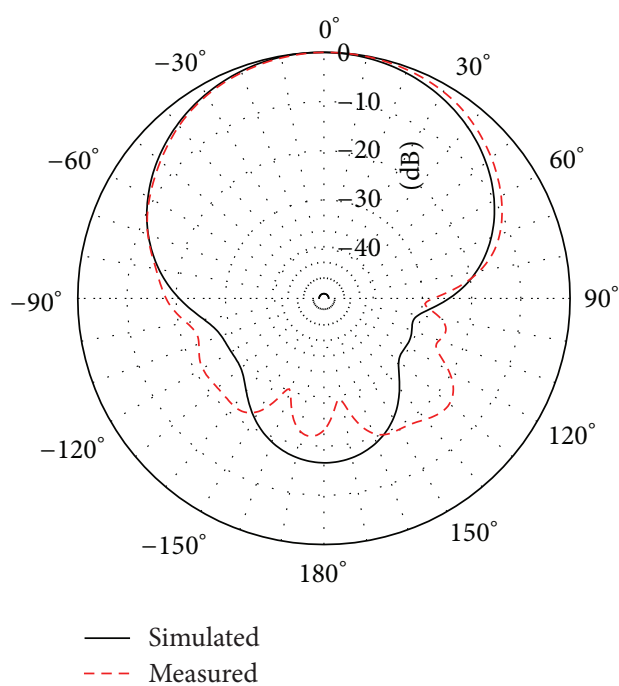

(a)

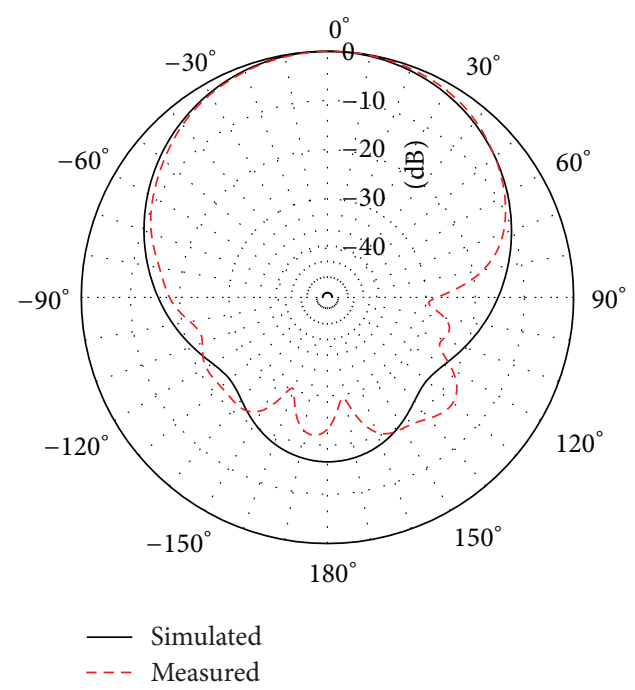

(b)

FIGURE 6: Comparison of simulated and measured copolarization radiation patterns in $E$-plane (a) and $H$-plane (b) in the band GSM 900.

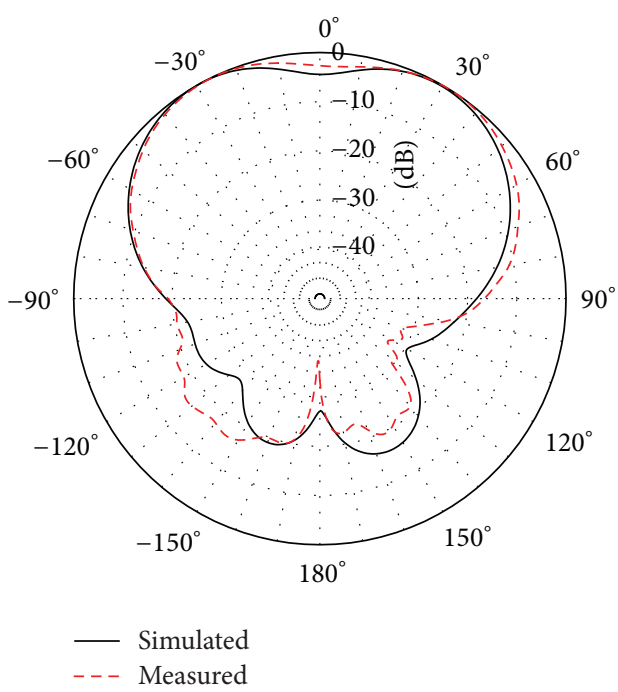

(a)

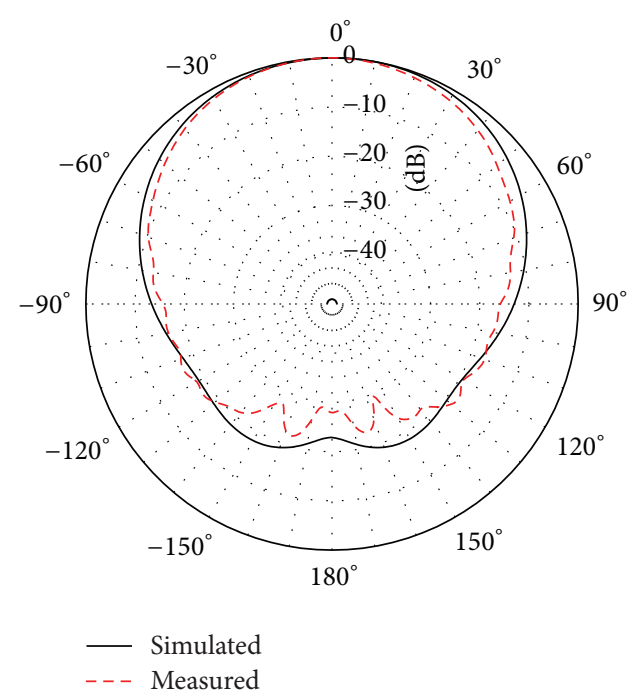

(b)

FIGURE 7: Comparison of simulated and measured copolarization radiation patterns in $E$-plane (a) and $H$-plane (b) in the band GSM 1800.

$3 \mathrm{G}$, and WiFi is shown in Figures 6, 7, 8, and 9, respectively. The $E$-plane corresponds with the $x z$ plane and the $H$-plane with the $y z$ plane in Figure 5.

\section{Double Koch Slot Loop Antenna}

In this part, we design a double Koch slot loop antenna, which is equivalent to the electrical monopole according to the duality theorem. The Koch fractal provides the opportunity to prolong the magnetic current line of the antenna. Therefore, we are able to design the antenna with smaller dimensions, while maintaining the same resonant frequency. The antenna structure is optimized to operate at two resonant frequencies $f_{1}=0.95 \mathrm{GHz}$ and $f_{2}=2.45 \mathrm{GHz}$. The antenna is simulated and optimized in CST Microwave Studio. Impedance matching and radiation pattern at two resonant frequencies are the main objectives of the design.

We follow the procedure of iterative synthesis of the Koch fractal described in [10]. The procedure allows prolonging the physical length of the designed structure by factor $(4 / 3)^{n}$, where $n$ is the number of the iteration, but the final dimension of the structure is still the same. The designed double slot loop antenna consists of two Koch snowflake shapes created from the third and second iteration of the Koch fractal, respectively (see Figure 10).

The largest loop [11] resonates at lower frequency $f_{1}=$ $0.95 \mathrm{GHz}$ and using the third iteration of Koch fractal. The length of this slot loop is given by $l_{1}=l \cdot(4 / 3)^{2}$, where $l$ indicates the length of a straight slot. The loop is interrupted 


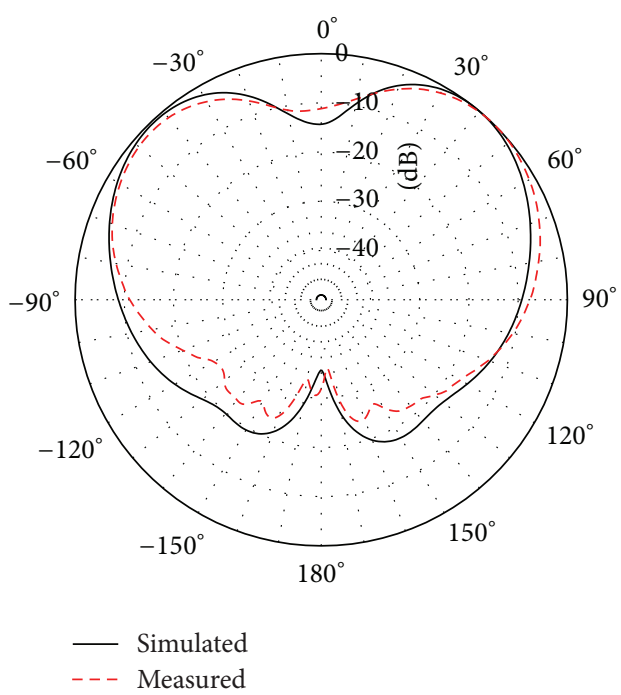

(a)

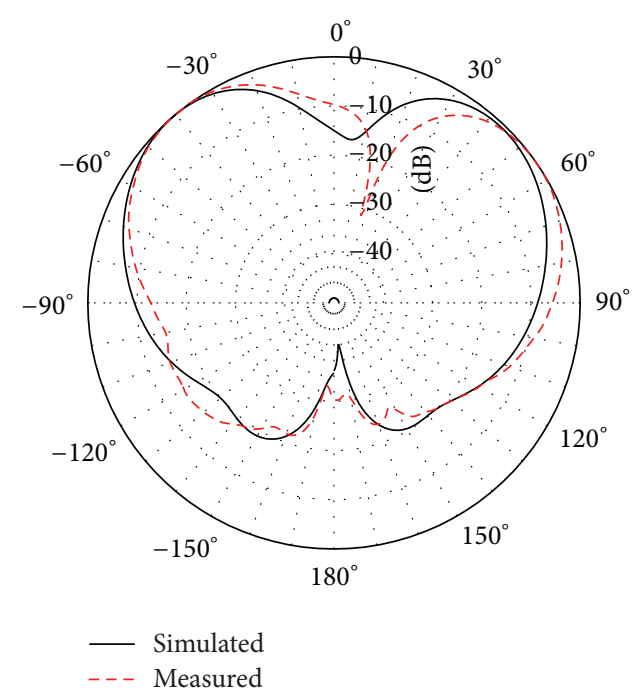

(b)

FIGURE 8: Comparison of simulated and measured copolarization radiation patterns in $E$-plane (a) and $H$-plane (b) in the $3 G$ band.

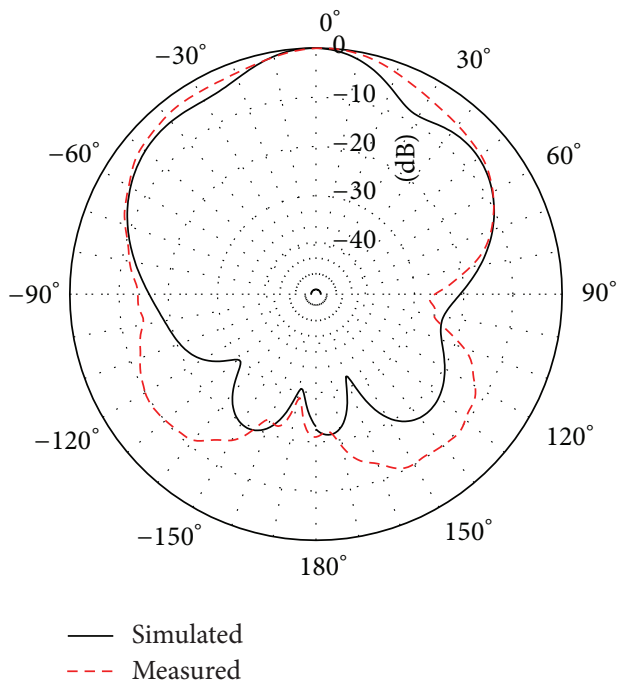

(a)

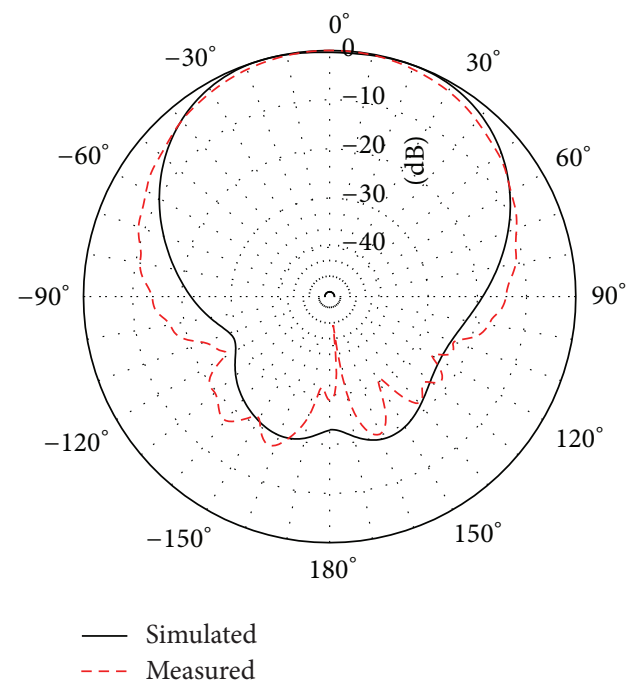

(b)

FIgURE 9: Comparison of simulated and measured copolarization radiation patterns in $E$-plane (a) and $H$-plane (b) in the WiFi band.

by a narrow strip of $2 \mathrm{~mm}$ width, which plays role of a serial susceptance in the circuit of a magnetic current used for tuning the input impedance of the antenna.

The smaller loop resonates at higher frequency $f_{2}=$ $2.45 \mathrm{GHz}$ and uses the second iteration of Koch fractal. Length of this slot loop is given by $l_{2}=l *(4 / 3)^{2}$, where $l$ indicates the length of a straight slot, but it is necessary to add small part of larger slot from feeding line to point of both slots connection. Both sides of this slot are incurved in the angle of 14.2 degrees because of connection on the top of the designed structure.

Total size of the antenna is $124 \mathrm{~mm} \times 105 \mathrm{~mm}$. The antenna was designed on the FR4 substrate with relative permittivity $\varepsilon_{r}=4.3$, dielectric loss tangent approximately $\tan \delta=0.02$, and height $h=0.762 \mathrm{~mm}$. We followed the procedure of the CPW feed design given in [12]. The prototype of the antenna was completed by a SMA connector.

The measured reflection coefficient of the designed antenna is depicted in Figure 3. The antenna covers the required bands with very good value of the reflection coefficient and a certain margin.

The radiation patterns were measured in one of the principal planes only due to the limitations of our measurement setup (i.e., the $E$-plane). It was impossible to mount the antenna in the test range in order to measure its $H$-plane. Due to this reason, simulated values are compared with measured ones for the E-plane in Figure 11. 
TABLE 1: Parameters of the proposed IFA antenna.

\begin{tabular}{|c|c|c|c|c|c|c|c|c|c|c|c|c|c|c|c|}
\hline Parameter & $l_{-} \mathrm{fed} 1$ & $l_{\_} \mathrm{fed} 2$ & l_fed3 & $l_{\_} \mathrm{fed} 4$ & $s$ & $a 1$ & $a 2$ & $b 1$ & $b 2$ & $c 1$ & $c 2$ & $d$ & $w_{\text {ssub }}$ & $l_{-}$sub & $l_{\text {_gnd }}$ \\
\hline Value (mm) & 17.40 & 31.32 & 23.42 & 14.43 & 2.31 & 56.55 & 36.26 & 14.35 & 8.67 & 30.78 & 11.59 & 1.00 & 102 & 56.33 & 23.55 \\
\hline
\end{tabular}

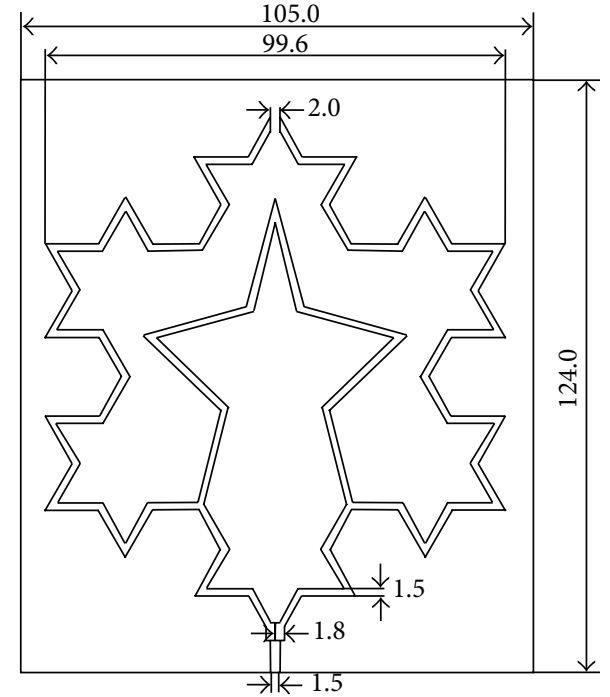

FIGURE 10: Geometrical configuration of the dual Koch slot antenna.

\section{Modified Dual-Band Inverted F Antenna (IFA)}

In recent years, the IFA antenna received particular attention as a promising candidate for decimeter-wave applications due to its simple structure, integration, small size, low profile, and low cost. From the viewpoint of size, the IFA arm covers larger space than a quarter of wavelength. The total antenna efficiency depends mainly on the impedance match between antenna and circuit and on losses in substrate [13, 14]. In IFA antenna, the size of the ground plane affects extensively the antenna performance [15].

The IFA seems a good candidate for energy harvesting due to its compact size, sufficient bandwidth, high efficiency, and relatively straightforward design. In [16], the first IFA for GSM and WiFi harvesting was presented. However, due to additional capacitor which was required, the antenna design ceased to be that simple.

In the following section, a dual-band IFA operating at both GSM bands is proposed. The design was taken from a classical inverted $\mathrm{F}$ antenna, which is used in the majority of mobile devices [15]. This antenna is based on the structure presented in [17]; a ground plane is placed on the opposite side from the planar metallic elements printed on the top of the substrate. The usage of two independent resonant elements at the desired GSM frequencies can be considered innovational. The top and bottom view of the proposed antenna are depicted in Figure 12. The antenna is created by 2 rectangular planar stubs placed at the opposite side of the ground plane achieving two fundamental resonant frequencies in both GSM bands: $0.9 \mathrm{GHz}$ (stub with length a1) and $1.8 \mathrm{GHz}$ (stub with length a2). Each individual stub is shorted by a metallic via. The short circuits are located on the left side. A coaxial SMA connector is used for feeding.

The proposed IFA antenna was designed for the GSM bands $0.9 \mathrm{GHz}$ and $1.8 \mathrm{GHz}$ using CST Microwave Studio on the substrate Arlon CuClad 217 with relative permittivity $\varepsilon_{r}=2.2$, loss tangent $\tan \delta=0.0009$ defined at $10 \mathrm{GHz}$, and thickness $h=1.524 \mathrm{~mm}$. The width of the stubs is established for sufficient impedance matching to the coaxial connector. The final dimensions of the proposed IFA antenna are stated in Table 1.

To verify the designed IFA antenna experimentally, the antenna was fabricated on a thin substrate. The top and bottom view of manufactured antenna with the coaxial connector are shown in Figure 12.

The measured reflection coefficient of the antenna is depicted in Figure 3. We can see that the fabricated antenna achieved relatively wide impedance bandwidth in both bands, $13.3 \%$ for the lower band and 15\% for the higher band.

Figure 13 shows the simulated and measured radiation pattern in the $E$-plane ( $y z$ plane in Figure 12$)$ at the frequencies $0.9 \mathrm{GHz}$ and $1.8 \mathrm{GHz}$. Measurement of the $H$-plane was not possible due to the limitations of our measurement setup. It can be seen that the measured radiation patterns are very similar to the simulated ones. The difference between the illustrated results is probably caused by scanner placement and absorber usage influencing the radiation pattern. Only the copolarized component of the radiation was measured. The realized gain of the measured antenna is $2 \mathrm{dBi}$ at the frequency $0.9 \mathrm{GHz}$ and $3.6 \mathrm{dBi}$ at the frequency $1.8 \mathrm{GHz}$.

The simulated total efficiency did not drop below $90 \%$ in the frequency bands of interest (see Figure 4).

\section{Wideband Dielectric Resonator Antenna (DRA)}

The dielectric resonator antenna (DRA) [18] concept was selected as another candidate for suitable harvesting antenna. Its main advantages are high radiation efficiency, wideband operation, relatively omnidirectional radiation patterns, and so forth. Due to the size limitations, the antenna was designed to cover the downlink frequency bands of the following systems: GSM $1800(1.84 \mathrm{GHz})$, UMTS $2100(2.145 \mathrm{GHz})$, and $\mathrm{WiFi}(2.445 \mathrm{GHz})$. The required relative bandwidth covering all the mentioned frequencies is approximately $28 \%$.

The designed DRA operated in the low order hybrid electromagnetic mode $\mathrm{HEM}_{11 \delta}$ of a cylindrical resonator providing a broadside radiation pattern with relatively low directivity and linear polarization. This mode could be excited by a current probe or by aperture coupling, but the latter method turned out to provide a more stable radiation pattern with frequency when the shape of the resonator was altered. The shape change was necessary in order to 


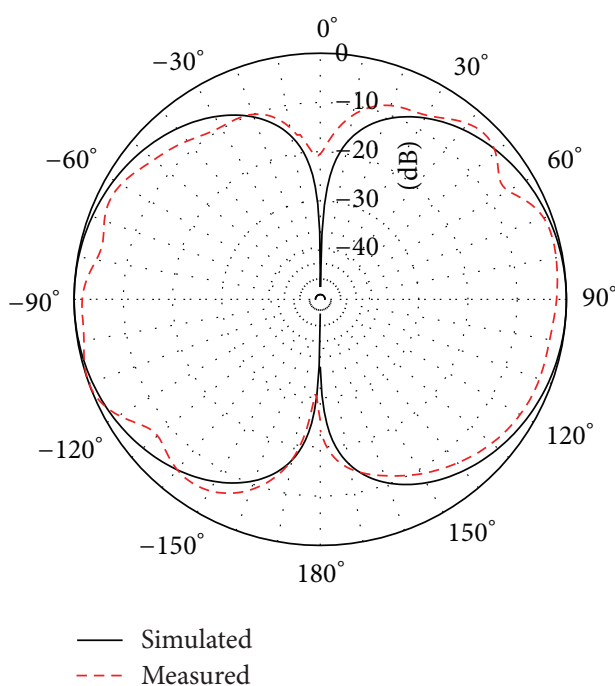

(a)

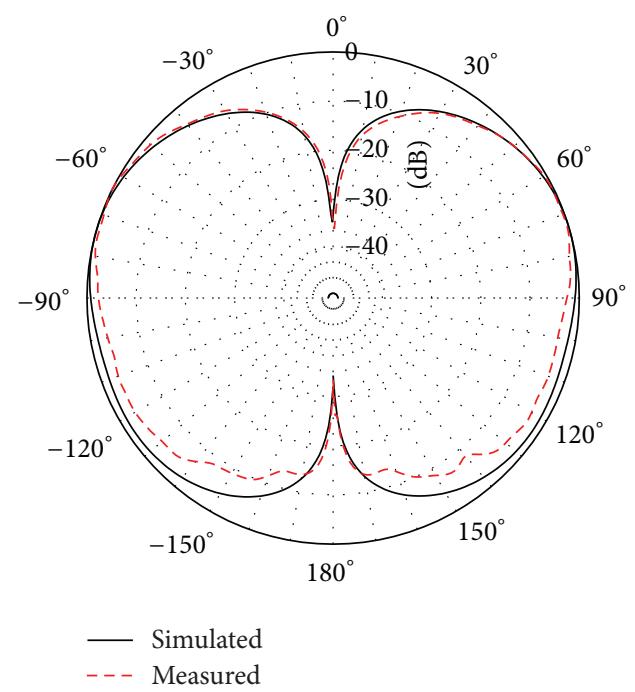

(b)

FIGURE 11: Comparison of simulated and measured copolarization radiation patterns in E-plane in the bands GSM 900 (a) and WiFi (b).

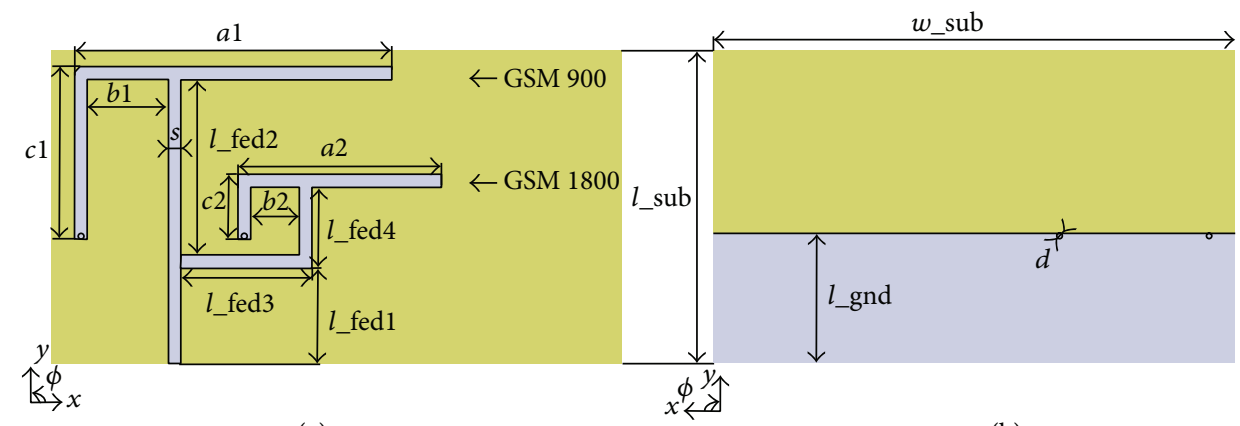

(a)

(b)

FIGURE 12: Geometrical configuration of the proposed antenna: top view (a) and bottom view (b).

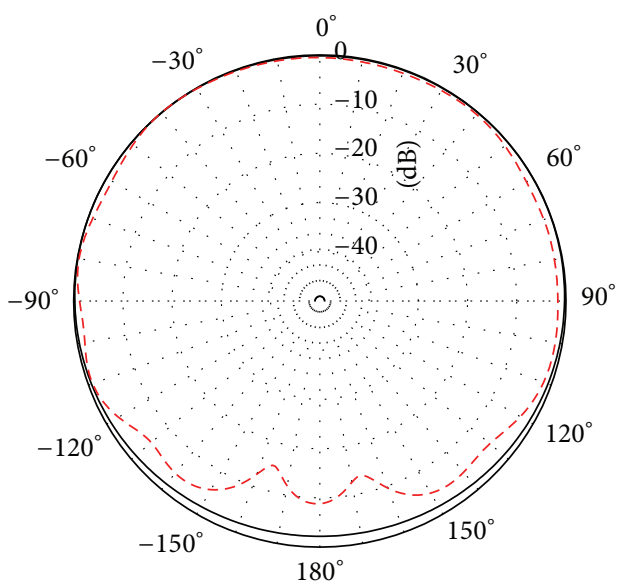

- Simulated

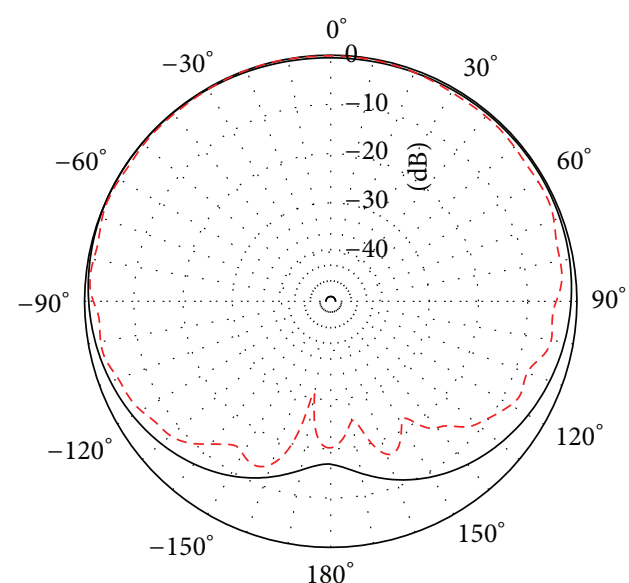

- Simulated

- . - Measured

(a)

(b)

FIGURE 13: Comparison of simulated and measured copolarization radiation patterns in E-plane in the bands GSM 900 (a) and GSM 1800 (b). 


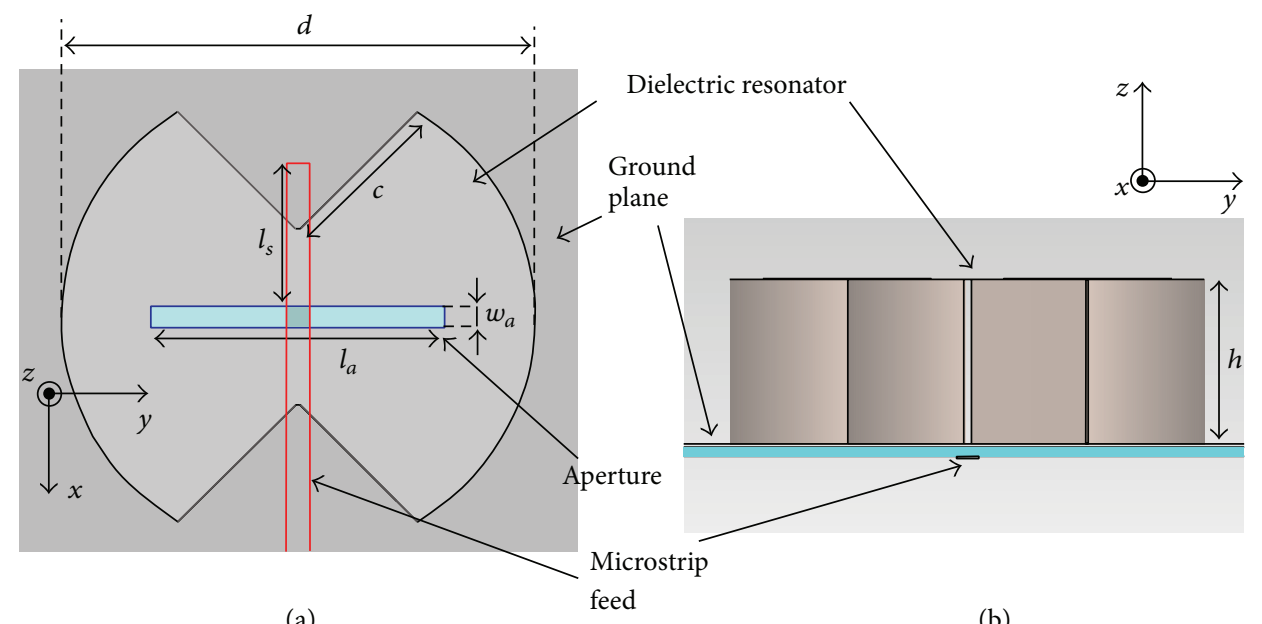

(a)

(b)

FIGURE 14: Geometry of the DRA antenna: top view (a) and side view (b).

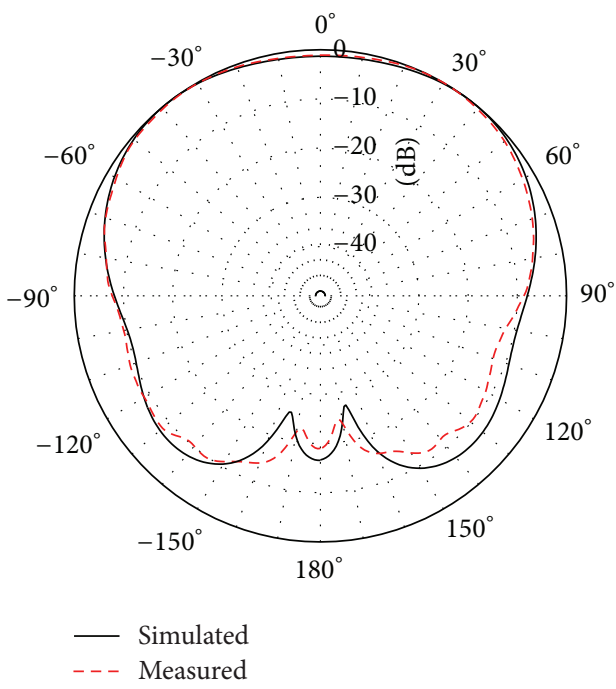

(a)

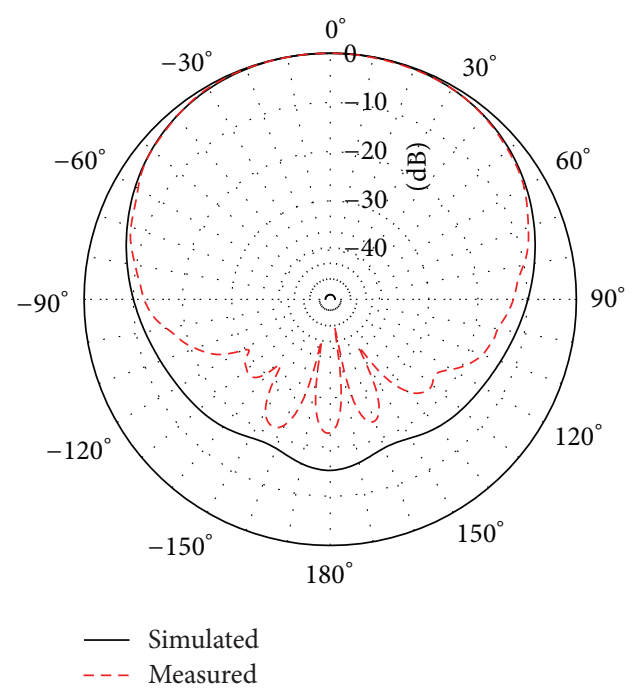

(b)

FIGURE 15: Comparison of simulated and measured copolarization radiation patterns in E-plane (a) and in $H$-plane (b) in the band GSM 1800.

provide increased bandwidth [19]; in our case the rectangular notches in the basic cylindrical resonator were carved out, thus resulting in a bow-tie shaped dielectric structure [20]. The resonator was placed above the ground plane and by changing the size of the ground plane, the radiation pattern could be further modified: that is, two maxima in one of the principal planes were obtainable. This seemed to be another interesting property of the DRA antenna for energy harvesting applications.

The DRA was constructed by stacking up etched layers of microwave substrate Arlon AR600 with height $h=$ $1.575 \mathrm{~mm}$, relative permittivity $\varepsilon_{r}=6.15$, and loss tangent $\tan \delta=0.003$. The individual layers of the substrate were kept together with double sided duct tape (50 $\mu \mathrm{m}$ thickness, $\varepsilon_{r} \approx 3$ ). In the design stage, the height of the resonator had to be an integer multiple of the available substrate thickness.
In order to keep the dimensions of the DRA relatively small and at the same time obtain desired bandwidth, the height of the resonator was selected to be $25.2 \mathrm{~mm}$ (i.e., 16 layers of substrate). The structure was optimized by varying three main parameters: diameter of the resonator, notch size, and aperture size.

The measured reflection coefficient of the antenna is compared with the other antenna elements in Figure 3. Simulation results of the radiation patterns were verified by measurements at three frequencies of interest $1.84 \mathrm{GHz}$, $2.145 \mathrm{GHz}$, and $2.445 \mathrm{GHz}$ and the results are displayed in Figures 15, 16, and 17. Only the copolarized component was measured and it corresponds to the vertical polarization (plane including apexes of notches $-x z$ plane in Figure 14). The $E$-plane corresponds to the $x z$ plane and $H$-plane to the $y z$ plane according to Figure 14. The simulated radiation 


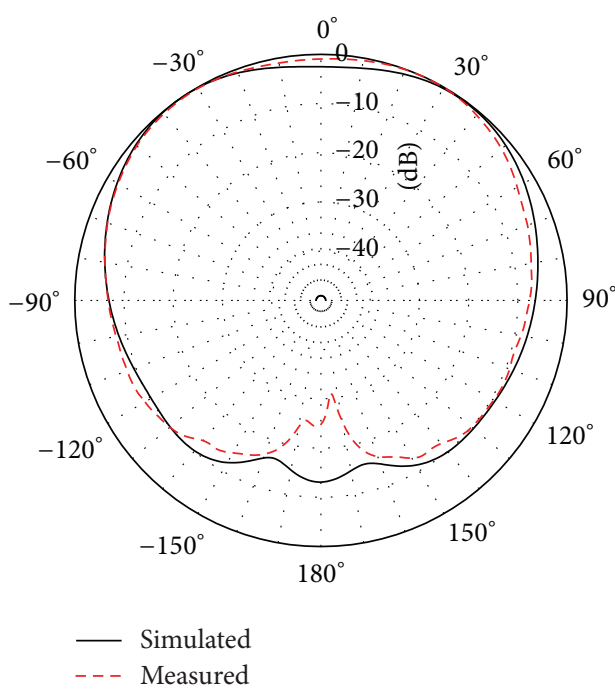

(a)

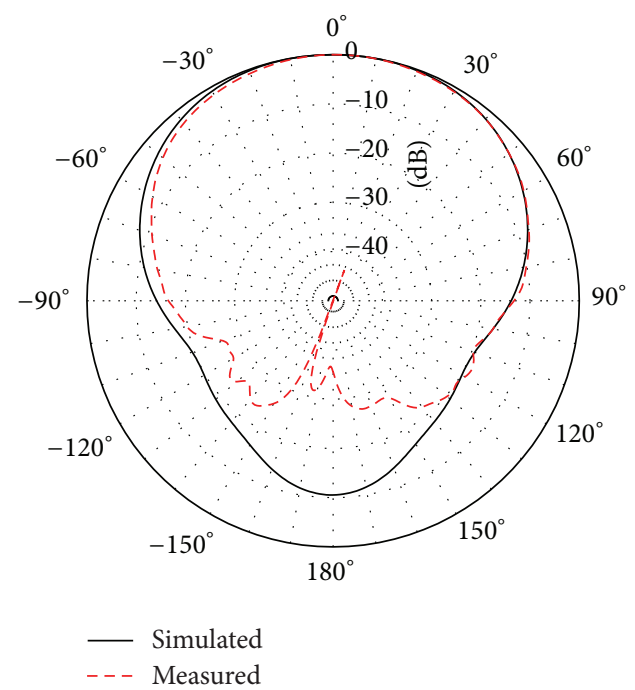

(b)

FIGURE 16: Comparison of simulated and measured copolarization radiation patterns in $E$-plane (a) and in $H$-plane (b) in the band 3G.

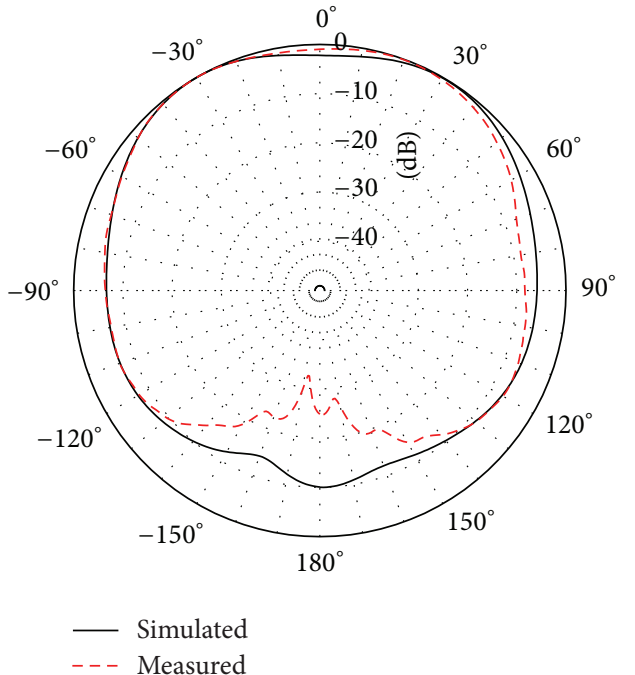

(a)

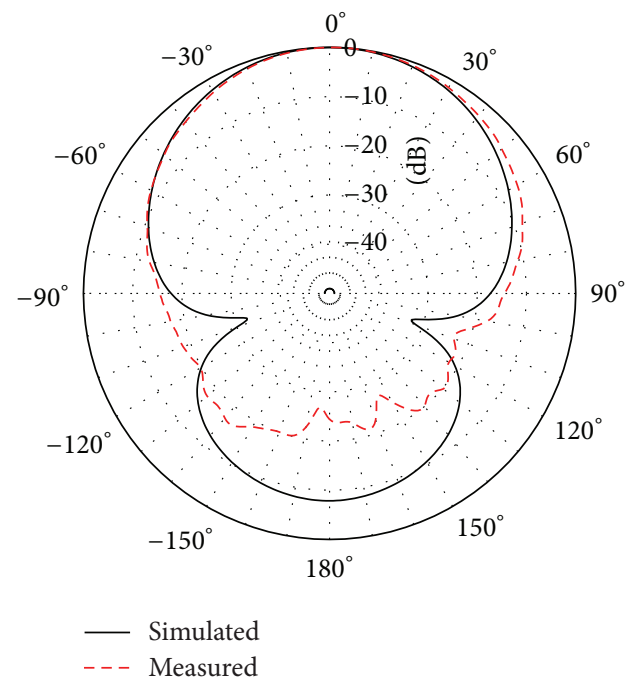

(b)

FIGURE 17: Comparison of simulated and measured copolarization radiation patterns in E-plane (a) and in $H$-plane (b) in the band WiFi.

TABLE 2: Dimensions of the designed DRA antenna.

\begin{tabular}{lcccccc}
\hline Parameter & $d$ & $h$ & $l_{s}$ & $l_{a}$ & $w_{a}$ & $c$ \\
\hline Value $(\mathrm{mm})$ & 72.8 & 25.2 & 23.2 & 56.1 & 4.32 & 25.0 \\
\hline
\end{tabular}

efficiency of the antenna was above $96 \%$ in the whole band of interest. The final dimensions of the antenna are given in Table 2.

\section{RF Measurement}

In order to determine the available RF energy, all types of proposed antennas for energy harvesting were used. Spectral measurements were taken from 13:00 to 14:00, during working day on September 2015 in the campus of Brno University of Technology (Brno, Czech Republic) using the R\&S ${ }^{\circledR} F S H$ handheld spectrum analyzer and described antennas. All of the measurements were carried out indoors (see Figure 19); hence, considerable high power values in WiFi band were obtained. For connection between antennas and spectrum analyzer, cables with nominal attenuation $0.1 \mathrm{~dB}$ were used. The measurement setup is depicted in Figure 18. During the measurements the antennas were rotated in all the angles of azimuth and elevation and the spectrum analyzer was set to "max hold" to ensure that the maximum instantaneous power level inside the band of interest was captured for particular 
TABLE 3: Overview of measured RF sources.

\begin{tabular}{lcccc}
\hline & GSM 900 & GSM 1800 & 3G & Wi-Fi \\
\hline Uplink [MHz] & $890-915$ & $1710-1784$ & $1920-1980$ & \multirow{2}{*}{$2400-2485$} \\
Downlink [MHz] & $935-960$ & $1805-1879$ & $2110-2170$ & \\
\hline
\end{tabular}

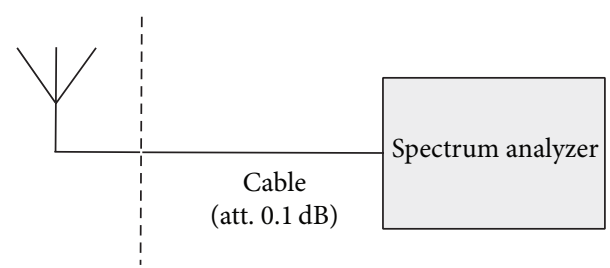

FIGURE 18: Block diagram of the measurement setup. All the described antennas were connected to the spectrum analyzer sequentially.

location. The power levels were measured in frequency bands according to Table 3.

Finally, GSM 900, GSM 1800, 3G, and WiFi (see Table 3 and Figure 20) are main candidates for sources of RF energy. Mentioned sources are practically available in most territories in Europe and they are dependent on atmospheric conditions, user traffic, and distance between the transmitter and user location. Therefore, practically utilizable power levels in GSM and 3G systems are limited. For indoor applications, powering through $2.4 \mathrm{GHz}$ WiFi network seems to be most suitable.

\section{Conclusion}

A very important component of every harvesting device is the antenna for which its performance has direct impact on the efficiency of the whole harvester; hence, the selection and proper antenna design must be approached with particular care.

Four different well-known antenna elements were studied in this paper and their suitability for harvesting applications was discussed and compared. The paper focused on three multiband antennas, namely, the patch antenna, the fractal slot antenna, and the modified inverted $\mathrm{F}$ antenna, and on the dielectric resonator antenna as a representative of wideband antennas. The antenna structures provided omnidirectional or hemispherical radiation patterns with high radiation efficiencies at frequencies of interest. Sufficient bandwidth in terms of input impedance matching was achieved as well.

All the structures under investigation proved to be quite promising for their utilization in RF energy harvesting. Nevertheless, further miniaturization of these basic antenna concepts is paramount if they are to be incorporated into compact devices such as sensor nodes or mobile/wearable electronics. Preservation of high radiation efficiency of these antennas when undergoing miniaturization will probably be the major challenge that must be resolved.

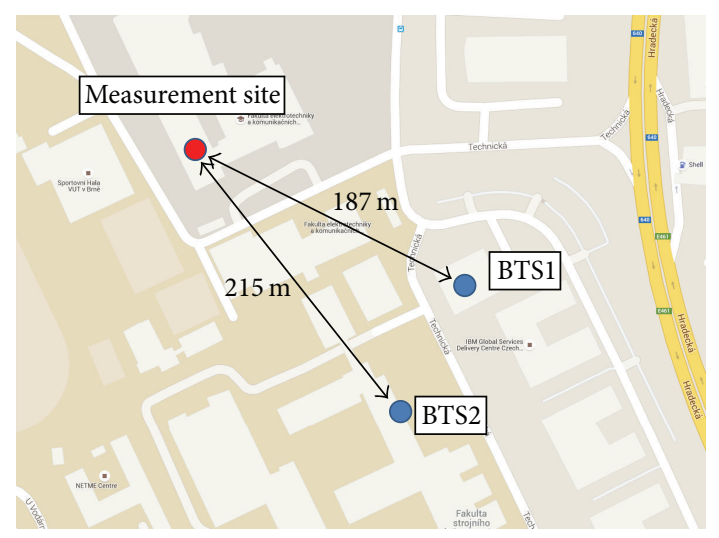

FIgURE 19: Measurement site location and distances to two nearest base stations.

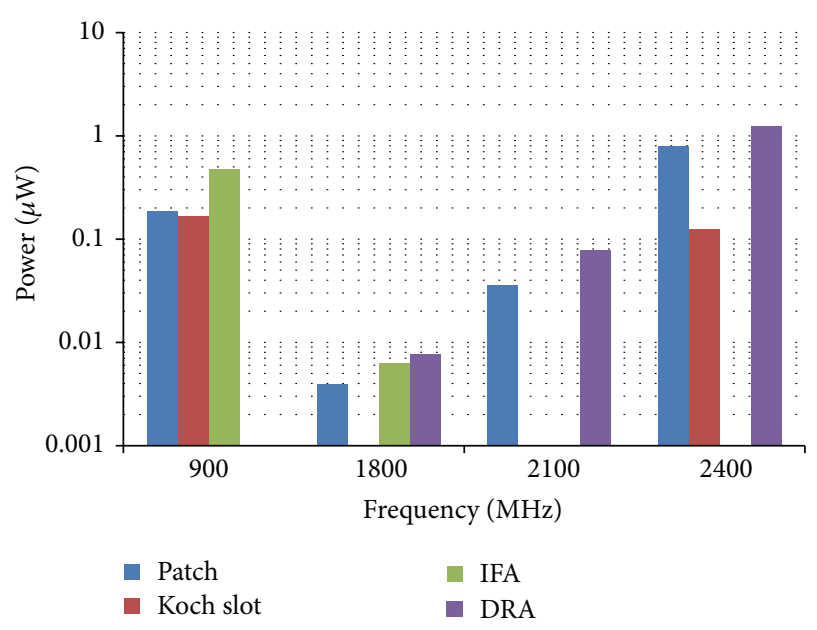

FIGURE 20: Measurement campaign results of various RF harvesting sources with the antennas described in the paper.

\section{Competing Interests}

The authors declare that there are no competing interests regarding the publication of this paper.

\section{Acknowledgments}

Research described in this paper was financially supported by the Czech Science Foundation under Grant no. P102/12/1274. The research was a part of the COST Action IC1301 WiPE supported by the Czech Ministry of Education under Grant LD14057. The presented research was supported by the Internal Grant Agency of Brno University of Technology Project no. FEKT-s-14-2483. The presented research was financed by Czech Ministry of Education in frame of National Sustainability Program under Grant LO1401. For research, infrastructure of the SIX Center was used. 


\section{References}

[1] C. R. Valenta and G. D. Durgin, "Harvesting wireless power: survey of energy-harvester conversion efficiency in far-field, wireless power transfer systems," IEEE Microwave Magazine, vol. 15, no. 4, pp. 108-120, 2014.

[2] J. A. Paradiso and T. Starner, "Energy scavenging for mobile and wireless electronics," IEEE Pervasive Computing, vol. 4, no. 1, pp. 18-27, 2005.

[3] P. Nintanavongsa, U. Muncuk, D. R. Lewis, and K. R. Chowdhury, "Design optimization and implementation for RF energy harvesting circuits," IEEE Journal on Emerging and Selected Topics in Circuits and Systems, vol. 2, no. 1, pp. 24-33, 2012.

[4] Product Datasheet, P2110-915 MHz RF Powerharvester ${ }^{\mathrm{TM}}$ Receiver, Powercast Corporation, Pittsburgh, Pa, USA, 2010.

[5] K. K. A. Devi, S. Sadasivam, N. M. Din, and C. K. Chakrabarthy, "Design of a $377 \Omega$ patch antenna for ambient RF energy harvesting at downlink frequency of GSM 900," in Proceedings of the 17th Asia Pacific Conference on Communications (APCC '11), pp. 492-495, Sabah, Malaysia, October 2011.

[6] R. A. Rahim, F. Malek, S. F. W. Anwar, S. L. S. Hassan, M. N. Junita, and H. F. Hassan, "A harmonic suppression circularly polarized patch antenna for an RF ambient energy harvesting system," in Proceedings of the IEEE Conference on Clean Energy and Technology (CEAT '13), pp. 33-37, IEEE, Lankgkawi, Malaysia, November 2013.

[7] M. Krakauskas, A. M. A. Sabaawi, and C. C. Tsimenidis, "Suspended patch microstrip antenna with cut rectangular slots for RF energy harvesting," in Proceedings of the 10th Loughborough Antennas and Propagation Conference (LAPC '14), pp. 304-307, Loughborough, UK, November 2014.

[8] A. M. A. Sabaawi and C. C. Tsimenidis, "Circular truncated patch antennas for energy harvesting applications," in Proceedings of the Loughborough Antennas and Propagation Conference (LAPC '13), pp. 369-373, Loughborough, UK, November 2013.

[9] A. Mavaddat, S. H. M. Armaki, and A. R. Erfanian, "Millimeterwave energy harvesting using $4 \times 4$ microstrip patch antenna array," IEEE Antennas and Wireless Propagation Letters, vol. 14, pp. 515-518, 2015.

[10] C. P. Baliarda, J. Romeu, and A. Cardama, "The Koch monopole: a small fractal antenna," IEEE Transactions on Antennas and Propagation, vol. 48, no. 11, pp. 1773-1781, 2000.

[11] V. Hebelka and Z. Raida, "Koch slot loop antenna for wireless body-centric communication," Microwave and Optical Technology Letters, vol. 56, no. 3, pp. 764-766, 2014.

[12] C. B. Wadell, Transmission Line Design Handbook, Artech House, Boston, Mass, USA, 1991.

[13] J. H. Kim, W. W. Cho, and W. S. Park, "A small dual-band inverted-F antenna with a twisted line," IEEE Antennas and Wireless Propagation Letters, vol. 8, pp. 307-310, 2009.

[14] M. Gallo, O. Losito, V. Dimiccoli, D. Barletta, and M. Bozzetti, "Design of an inverted F antenna by using a transmission line model," in Proceedings of the 5th European Conference on Antennas and Propagation (EUCAP '11), pp. 635-638, IEEE, Rome, Italy, April 2011.

[15] M.-C. Huynh and W. Stutzman, "Ground plane effects on planar inverted-F antenna (PIFA) performance," IEE Proceedings: Microwaves, Antennas and Propagation, vol. 150, no. 4, pp. 209$213,2003$.

[16] M. H. Hoang, H. P. Phan, T. Q. V. Hoang, and T.-P. Vuong, "Efficient compact dual-band antennas for GSM and Wi-Fi energy harvesting," in Proceedings of the 7th International Conference on Advanced Technologies for Communications (ATC '14), pp. 401-404, Hanoi, Vietnam, October 2014.

[17] O. Losito, V. Dimiccoli, and D. Barletta, "Meander-line inverted F antenna designed using a transmission line model," in Proceedings of the 8th European Conference on Antennas and Propagation (EuCAP '14), pp. 1370-1373, The Hague, The Netherlands, April 2014.

[18] K. M. Luk and K. W. Leung, Dielectric Resonator Antennas, Research Studies Press, Baldock, UK, 2003.

[19] J. T. H. St Martin, Y. M. M. Antar, A. A. Kishk, A. Ittipiboon, and M. Cuhaci, "Dielectic resonator antenna using aperture coupling," Electronics Letters, vol. 26, no. 24, pp. 2015-2016, 1990.

[20] L. Z. Thamae and Z. Wu, "Broadband bowtie dielectric resonator antenna," IEEE Transactions on Antennas and Propagation, vol. 58, no. 11, pp. 3707-3710, 2010. 


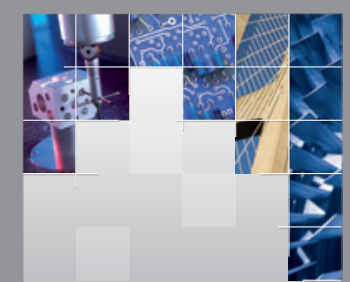

\section{Enfincering}
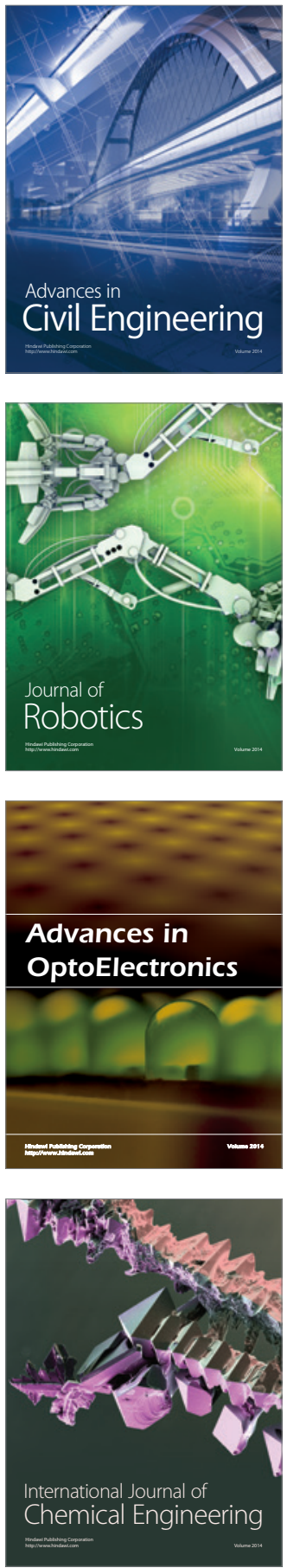

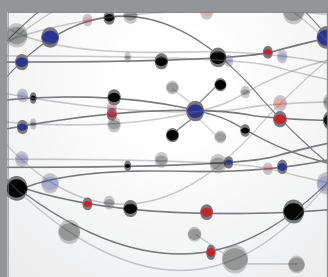

The Scientific World Journal

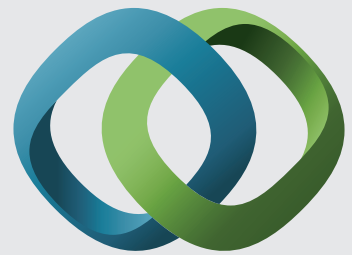

\section{Hindawi}

Submit your manuscripts at

http://www.hindawi.com
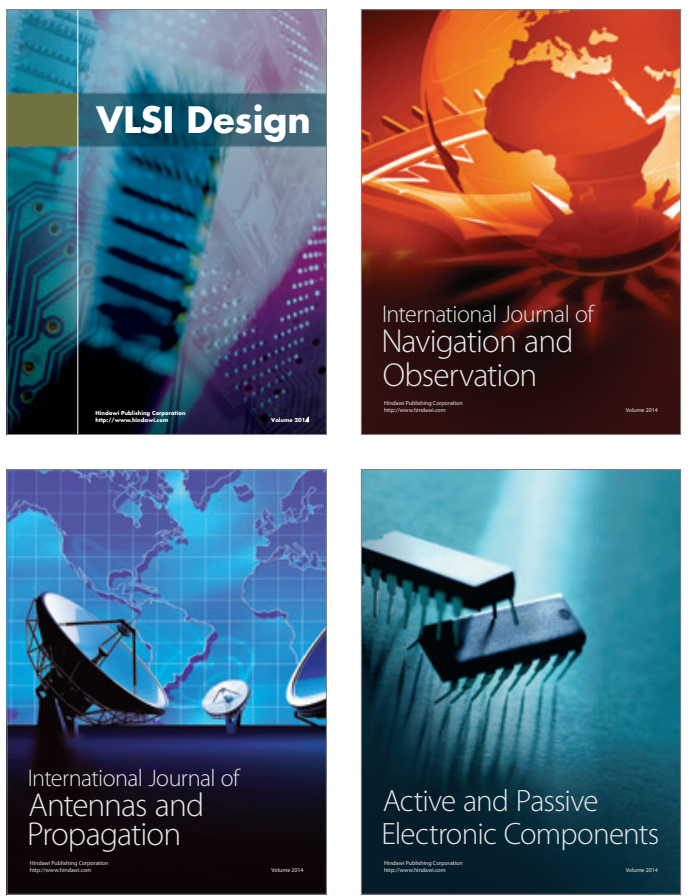
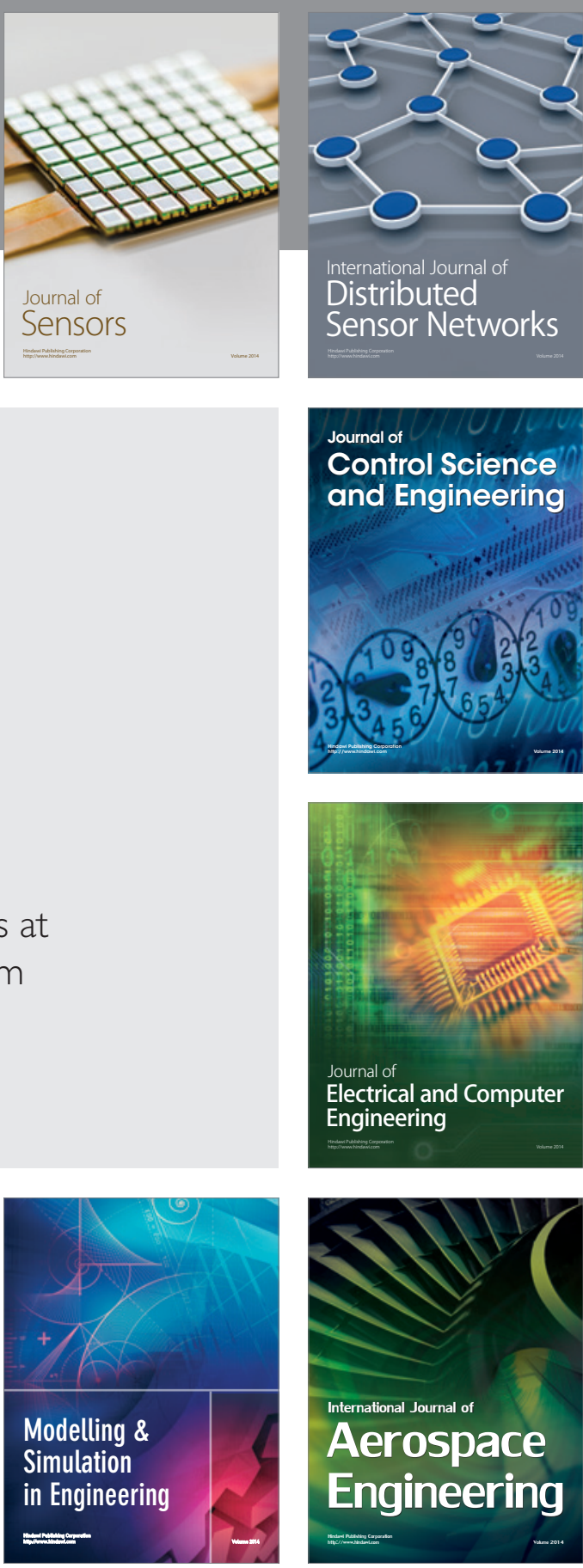

International Journal of

Distributed

Sensor Networks

Journal of

Control Science

and Engineering
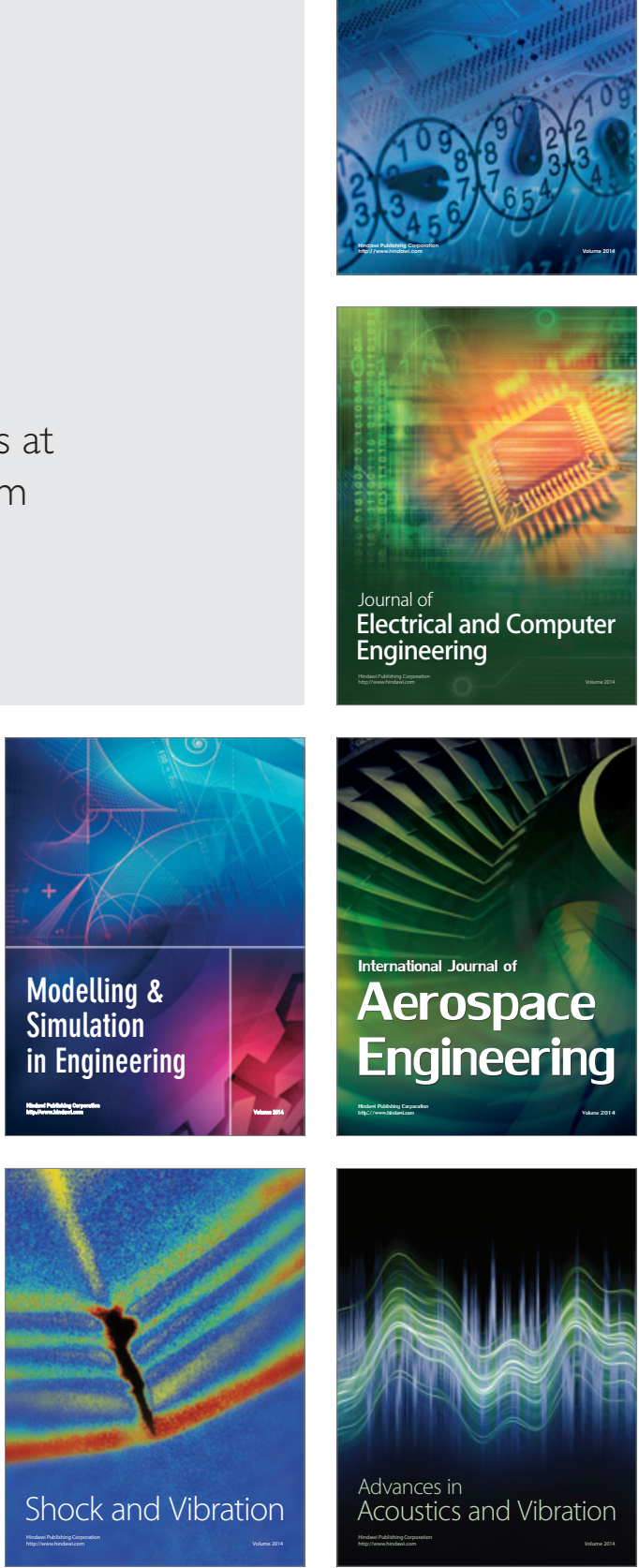